\title{
Short-term use of atorvastatin affects glucose homeostasis and suppresses the expression of LDL receptors in the pancreas of mice
}

\author{
QI YU ${ }^{1,2}$, FANG WANG $^{2}$, XIAODONG MENG $^{2}$, YIREN GONG $^{2}$, \\ YANLI WANG ${ }^{2}$, CANGBAO XU $^{2}$ and SIWANG WANG ${ }^{1}$ \\ ${ }^{1}$ Institute of Material Medical, School of Pharmacy, The Fourth Military Medical University, Xi'an, Shaanxi 710032; \\ ${ }^{2}$ Shaanxi Key Laboratory of Ischemic Cardiovascular Diseases and Institute of Basic and Translational Medicine, \\ Xi'an Medical University, Xi'an, Shaanxi 710021, P.R. China
}

Received November 30, 2017; Accepted May 3, 2018

DOI: $10.3892 / \mathrm{mmr} .2018 .9239$

\begin{abstract}
Low-density lipoprotein receptors (LDLRs) may serve a role in the diabetogenic effect of statins; however, the effects of statins on LDLR expression and its regulation in the pancreas and islets have yet to be determined. To exclude the long-term effects of treatment with atorvastatin, which allows mice to adapt, male C57BL/j and apolipoprotein E-deficient mice were acutely treated with oral atorvastatin for 6 weeks, and glucose homeostasis and LDLR expression in the pancreas and islets were examined. In the present study, it was observed that the short-term use of atorvastatin affected insulin sensitivity in normal mice and glucose tolerance in hyperlipidemic mice. Furthermore, it was identified that 6 weeks of treatment with atorvastatin suppressed LDLR expression in the pancreas and pancreatic islets in $\mathrm{C} 57 \mathrm{BL} / \mathrm{j}$ mice, and an increase in proprotein convertase subtilisin/kexin type 9 expression was additionally observed in the pancreas. However, 6 weeks of treatment with atorvastatin did not affect LDLR expression in the pancreas of hyperlipidemic mice. It may be concluded that the short-term use of atorvastatin disturbs glucose homeostasis and suppresses LDLR expression in the pancreas and pancreatic islets in $\mathrm{C} 57 \mathrm{BL} / \mathrm{j}$ mice, suggesting that the role of LDLR in the diabetogenic effect of statins requires further investigation.
\end{abstract}

\section{Introduction}

Hyperlipidemia is strongly associated with the prevalence of type 2 diabetes mellitus (T2DM), and statins are the first line of drugs for treating hyperlipidemia. However, a previous study

Correspondence to: Professor Siwang Wang, Institute of Material Medical, School of Pharmacy, The Fourth Military Medical University, 169 Changle West Road, Xi'an, Shaanxi 710032, P.R. China

E-mail:wangsiw@fmmu.edu.cn

Key words: type 2 diabetes mellitus, atorvastatin, low-density lipoprotein receptor, mouse model demonstrated that statins may increase the risk of new-onset T2DM, and the underlying mechanism requires determination (1). Notably, a series of studies on patients with familial hypercholesterolemia $(\mathrm{FH})$ have investigated this $(2,3)$. In these studies, a novel phenomenon demonstrated that patients with FH were protected against diabetes mellitus even when subjected to long-term statin therapy. Considering that the majority of the patients in these studies had a heterozygous mutation in the low-density lipoprotein receptor (LDLR) gene, these findings suggest a noteworthy hypothesis that LDLR-mediated cholesterol metabolism may be involved in the diabetogenic effect of statins (4). Indeed, statins may enhance cholesterol uptake in the liver and peripheral tissues via upregulation of LDLR and thereby reduce plasma levels of LDL-cholesterol (C) in the blood. Overaccumulation of cholesterol in peripheral tissues may cause lipotoxicity, which promotes a negative effect on the function of the pancreatic islets as previously described (5). Additionally, cholesterol impairs the function of pancreatic $\beta$ cells and causes cellular apoptosis, which have been demonstrated in in vitro and in vivo studies (6).

Although LDLRs may provide a key association between statin therapy and the risk of new-onset T2DM, whether LDLR expression and its regulation in the pancreas and pancreatic islets are altered when patients receive statins is unknown (2). A previous study conducted by the present team demonstrated that 16 weeks of oral treatment with atorvastatin did not affect glucose metabolism in rabbits (7). Therefore, it was hypothesized that the short-term use of atorvastatin may disturb glucose homeostasis. Accordingly, it was proposed that the short-term use of statins may affect the function of pancreatic islets via regulation of LDLR expression. Therefore, the present study aimed to elucidate glucose homeostasis, LDLR expression and its possible regulation in the pancreas following the short-term administration of atorvastatin.

\section{Materials and methods}

Animals. The present study was conducted in accordance with the Guidelines for Animal Experimentation of Xi'an Medical University (Xi'an, China) and the Guide for the Care and Use of Laboratory Animals published by the US National 
Institutes of Health (NIH; Bethesda, MD, USA; NIH publication no. 85-23, revised 2011). The experimental protocols were approved by the Laboratory Animal Administration Committee of Xi'an Medical University (Institutional Animal Care and Use Committee; permit no. XYJZS-1207011). Male C57BL/6j mice (12 weeks old; $30 \mathrm{~g}$ ) were obtained from the laboratory animal center at The Fourth Military Medical University (Xi'an, China), and male apolipoprotein E (ApoE)-deficient mice (12 weeks old; 30 g) were obtained from the laboratory animal center at Xi'an Jiaotong University (Xi'an, China). A total of $20 \mathrm{C} 57 \mathrm{BL} / 6 \mathrm{j}$ mice were randomly divided into two groups and received a normal chow diet. One group was treated with atorvastatin via intragastric administration (10 mg/kg, each day; Sigma-Aldrich; Merck $\mathrm{KGaA}$, Darmstadt, Germany) for 6 weeks; the other group was given the same dose of double distilled water. A total of 16 ApoE-deficient mice were additionally divided into two groups and received a high-fat diet in addition to the treatment described above. As previously suggested by Capel et al (8), a $10 \mathrm{mg}$ dose of atorvastatin has been repeatedly demonstrated to be effective on lipid metabolism in mice, and the relevant literature is listed in Table I (8-17). All mice were individually housed in plastic cages $(30 \times 20 \times 13 \mathrm{~cm})$ throughout the extent of the present study and maintained on a 12/12 h light/dark cycle (light off at noon) at constant temperature $\left(22^{\circ} \mathrm{C}\right)$ with $10-15$ hly cycles of fresh air and relative humidity $(60 \pm 10 \%)$. Food and water were available ad libitum.

Plasma lipid, glucose and insulin metabolism. Following overnight fasting, blood samples were collected via the retro-orbital sinus in tubes containing EDTA as an anticoagulant. Blood samples were centrifuged $\left(1,500 \mathrm{x} \mathrm{g} ; 15 \mathrm{~min} ; 4^{\circ} \mathrm{C}\right)$ to collect plasma. Plasma total cholesterol (TC), total triglycerides (TG) and high-density lipoprotein (HDL-C) were measured using a Varioskan Flash plate reader (Thermo Fisher Scientific, Inc., Waltham, MA, USA) with assay kits (BioSino Bio-Technology and Science Inc., Beijing, China) during the final week of the treatment as previously described (18). Intravenous glucose tolerance tests (IGTT) and intravenous insulin tolerance tests (IITT) were performed as previously described (7). The mice were injected with an intravenous glucose solution following $12 \mathrm{~h}$ of fasting, and the blood samples were subsequently drawn at $0,15,30,60,90,120$ and $150 \mathrm{~min}(1.5 \mathrm{~g} / \mathrm{kg}$ body weight $)$. For IITT, subsequent to the intravenous injection of insulin (1 U/kg body weight; Wanbang Biopharmaceuticals Co., Ltd., Xuzhou, China), blood samples were collected to examine blood sugar levels at 0,15, 30, 60, 90, 120 and $150 \mathrm{~min}$.

RNA extraction and reverse transcription-quantitative polymerase chain reaction $(R T-q P C R)$. Total RNA of the pancreas and liver were extracted using RNAiso Plus (Takara Bio, Inc., Otsu, Japan). RT-qPCR was performed and quantified using the $2^{-\Delta \Delta \mathrm{Cq}}$ method as previously described (18-20). The sequences of the primers are listed as follows: LDLR, 5'-TGACCTTCATCCCAGAGCCTTC-3' and 5'-GGCATGAGCGGGTATCCATC-3'; proprotein convertase subtilisin/kexin type 9 (PCSK9), 5'-TATCCCAGCATGGCA CCAGA-3' and 5'-ATGGTGACCCTGCCCTCAA-3'; sterol regulatory element-binding protein 2 (SREBP-2), 5'-CCCTTG ACTTCCTTGCTGCA-3' and 5'-GCGTGAGTGTGGGCG
AATC-3'; E3 ubiquitin-protein ligase MYLIP (IDOL), 5'-AGG AGATCAACTCCACCTTCTG-3' and 5'-ATCTGCAGACCG GACAGG-3; GAPDH, 5'-ACTGAGGACCAGGTTGTC-3' and 5'-TGCTGTAGCCGTATTCATTG-3'.

Protein extraction and western blot analysis. Total protein was extracted from the pancreas and liver as previously described (19). The primary antibodies were against LDLR (1:500; cat. no. ab52818; Abcam, Cambridge, UK), ATP-binding cassette transporter A1 (ABCA1; 1:1,000; cat. no. sc-58219), SREBP-2 (1:1,000; cat. no. sc-271616; both Santa Cruz Biotechnology, Inc., Dallas, TX, USA), PCSK9 (1:1,000; cat. no. ab181142; Abcam), IDOL (1:2,000; cat. no. SAB4501317; Sigma-Aldrich; Merck KGaA) and GAPDH (1:2,000; cat. no. sc-32233; Santa Cruz Biotechnology, Inc.) overnight at $4^{\circ} \mathrm{C}$. Membranes were subsequently incubated with horseradish peroxidase-conjugated secondary antibodies (1:2,500; cat. nos. A0216 and A0208; Beyotime Institute of Biotechnology, Haimen, China) for $3 \mathrm{~h}$ at room temperature. A western blot analysis was performed as previously described, and relative protein expression was quantified by ImageJ (bundled with Java 1.8.0_172; NIH) (19).

Islet insolation and culture. Pancreatic islets in each mouse were isolated as previously described (21). Pancreatic islets were isolated from fasting mice with collagenase type $\mathrm{V}$ (0.8 mg/ml; Sigma-Aldrich; Merck KGaA) digestion and, subsequently, islets were purified using a continuous Histopaque (Sigma-Aldrich; Merck KGaA) gradient. Purified islet fractions were collected, and all islets (including islets with normal architecture and islets more or less affected by fibrosis) were selected under a stereomicroscope (magnification, x10). Mouse islets were cultured in RPMI 1640 medium (Invitrogen; Thermo Fisher Scientific, Inc.) and seeded on a 24-well plate (20 islets/well) coated with rat-tail collagen (Sigma-Aldrich; Merck KGaA). Islets were left in wells for $24 \mathrm{~h}$ to adhere and were subsequently treated with different concentrations of atorvastatin (0, 1, 10 and $100 \mathrm{nM}$; Sigma-Aldrich; Merck KGaA) for $48 \mathrm{~h}$, according to previously described protocols (22).

Immunofluorescence. Following $48 \mathrm{~h}$ of incubation, islets were fixed for $1 \mathrm{~h}$ with $4 \%$ formaldehyde at room temperature and were blocked with $5 \%$ bovine serum albumin (cat. no. P0007; Beyotime Institute of Biotechnology) in PBS for $1 \mathrm{~h}$ at room temperature. To avoid the detection of internalized LDLR in the intracellular lysosomes, islets were not permeabilized with Triton X-100 prior to incubation. Pancreatic islets were incubated overnight at $4^{\circ} \mathrm{C}$ with primary antibodies (1:500; cat. no. ab52818; Abcam) against LDLR, and the islets were incubated with Alexa Fluor 488 (1:2,000; cat no. Z25302; Thermo Fisher Scientific, Inc.) secondary antibodies for $3 \mathrm{~h}$ at room temperature. Pictures were taken on the fluorescent Nikon TE2000 Inverted Microscope (magnification, x4; TE2000S; Nikon Corporation, Tokyo, Japan) and analyzed with the ImageJ software as previously described (23).

ELISA. Plasma PCSK9 and insulin levels were measured using commercial ELISA kits (cat. no. MPC900; Mouse Quantikine 
Table I. Summary of atorvastatin doses in mouse models involving DM-associated research.

\begin{tabular}{|c|c|c|c|c|c|}
\hline Author, year & $\begin{array}{l}\text { PubMed-Indexed } \\
\text { for MEDLINE }\end{array}$ & $\begin{array}{l}\text { Atorvastatin dose, } \\
\text { intervention time, } \\
\text { mode of drug delivery }\end{array}$ & Mouse model & Purpose & (Refs.) \\
\hline Capel et al, 2015 & 26228176 & $\begin{array}{c}10 \mathrm{mg} / \mathrm{kg} / \mathrm{day}, 3 \text { weeks, } \\
\text { gastric gavage }\end{array}$ & C57BL/6J mice & $\begin{array}{l}\text { Diet-induced } \\
\text { obesity }\end{array}$ & (8) \\
\hline Liang et al, 2017 & 28214881 & $\begin{array}{c}10 \text { mg/kg/day, } 4 \text { weeks, } \\
\text { gastric gavage }\end{array}$ & Kunming mice & $\begin{array}{l}\text { The treatment of } \\
\text { myocardial hypertrophy }\end{array}$ & (9) \\
\hline Ren et al, 2016 & 27851811 & $\begin{array}{c}10 \mathrm{mg} / \mathrm{kg} / \text { day, } 12 \text { weeks, } \\
\text { osmotic mini pumps }\end{array}$ & C57BL/6J mice & $\begin{array}{l}\text { Experimental diabetic } \\
\text { cardiomyopathy }\end{array}$ & $(10)$ \\
\hline Wu et al, 2016 & 27428373 & $\begin{array}{c}10 \mathrm{mg} / \mathrm{kg} / \text { day, } 8 \text { weeks, } \\
\text { gastric gavage }\end{array}$ & ApoE-/-mice & Inflammatory stress & (11) \\
\hline Lee et al, 2016 & 27565724 & $\begin{array}{c}10 \mathrm{mg} / \mathrm{kg} / \text { day, } 7 \text { weeks, } \\
\text { gastric gavage }\end{array}$ & C57BL/6J mice & $\begin{array}{l}\text { Immune dysfunction } \\
\text { in metabolic disorders }\end{array}$ & (12) \\
\hline Roth et al, 2016 & 26826559 & $\begin{array}{c}10 \mathrm{mg} / \mathrm{kg} / \text { day, } 15 \text { weeks } \\
\text { gastric gavage }\end{array}$ & ApoE-/-mice & $\begin{array}{l}\text { Cardiovascular morbidity } \\
\text { and mortality }\end{array}$ & (13) \\
\hline Han et al, 2016 & 27574007 & $\begin{array}{c}10 \mathrm{mg} / \mathrm{kg} / \text { day, } 15 \text { weeks, } \\
\text { gastric gavage }\end{array}$ & ApoE-/-mice & $\begin{array}{l}\text { Atherogenesis and } \\
\text { plaque instability }\end{array}$ & (14) \\
\hline $\begin{array}{l}\text { Bruder-Nascimento et al, } \\
2015\end{array}$ & 25358739 & $\begin{array}{c}10 \mathrm{mg} / \mathrm{kg} / \text { day, } 3 \text { weeks, } \\
\text { gastric gavage }\end{array}$ & $\mathrm{db} / \mathrm{db}$ mice & Vascular injury in DM & (15) \\
\hline Park et al, 2015 & 26174316 & $\begin{array}{c}10 \mathrm{mg} / \mathrm{kg} / \text { day, } 12 \text { weeks, } \\
\text { gastric gavage }\end{array}$ & ApoE-/-mice & $\begin{array}{l}\text { Inflammatory and vascular } \\
\text { diseases in atherosclerosis }\end{array}$ & (16) \\
\hline $\begin{array}{l}\text { Van den Hoek } \\
\text { et al, } 2014\end{array}$ & 24373179 & $\begin{array}{c}10 \mathrm{mg} / \mathrm{kg} / \text { day, } 20 \text { weeks } \\
\text { gastric gavage }\end{array}$ & E3L.CETP mice & The metabolic syndrome & (17) \\
\hline
\end{tabular}

DM, diabetes mellitus; ApoE, apolipoprotein E.

ELISA for PCSK9; R\&D Systems, Inc., Minneapolis, MN, USA; cat. no. YK060; Insulin ELISA; Yanaihara Institute Inc., Fujinomiya, Japan) during the last week of intervention, as previously described (18).

Statistical analysis. All data are expressed as the mean \pm standard error. Comparisons between two groups were performed using the Student's t-test. Comparisons between multiple groups were conducted using one-way analysis of variance with the Bonferroni test. $\mathrm{P}<0.05$ was considered to indicate a statistically significant difference. The experiments were repeated three times and statistical calculations were analyzed using the SPSS 19.0 software (IBM Corp., Armonk, NY, USA).

\section{Results}

Short-term use of atorvastatin affects glucose homeostasis in mice with hyperlipidemia. To study the effect of acute atorvastatin administration on glucose metabolism, IGTT and IITT were performed following 3 and 6 weeks of treatment with atorvastatin in $\mathrm{C} 57 \mathrm{BL} / 6 \mathrm{j}$ mice. As demonstrated in Fig. 1A, a 3-week treatment with atorvastatin did not affect glucose tolerance, and only the glucose levels at time 0 (fasting state) were decreased in atorvastatin-treated mice. However, treatment with atorvastatin for 3 weeks significantly affected insulin tolerance following $50 \mathrm{~min}(\mathrm{P}<0.05)$ and significantly increased the AUC $(\mathrm{P}<0.05)$, indicating that atorvastatin decreased insulin sensitivity (Fig. 1A). However, when the
AUCs were compared, it was observed that treatment with atorvastatin for 6 weeks did not affect glucose tolerance or insulin sensitivity (Fig. 1B). Additionally, it was identified that treatment with atorvastatin for 6 weeks decreased insulin levels following $12 \mathrm{~h}$ of fasting (Fig. 1B).

As it is known that hyperlipidemia increases the risk of cardiovascular disease (CVD) and T2DM, it was hypothesized that the short-term use of atorvastatin may affect glucose metabolism in mice with hyperlipidemia (24). It was observed that treatment with atorvastatin for 6 weeks increased glucose tolerance in mice with hyperlipidemia (Fig. 2A); whereas, there was no marked effect on insulin sensitivity (Fig. 2B).

Short-term use of atorvastatin affects blood lipid levels in normal mice. The lipid profile was examined in the two types of mice following 6 weeks of treatment with atorvastatin. The present results demonstrated that treatment with atorvastatin significantly decreased the TC, TG and insulin levels in the C57BL/j mice compared with the control plasma lipid levels $(\mathrm{P}<0.05)$; however, there was no significant difference in plasma LDL-C, HDL-C or glucose (Fig. 3A). In hyperlipidemic mice, treatment with atorvastatin did not affect plasma TC, LDL-C, HDL-C, TG or glucose (Fig. 3B). This result is consistent with a previous study demonstrating that atorvastatin does not markedly reduce the blood lipid levels in ApoE-deficient mice (25). Furthermore, it was identified that treatment with atorvastatin for 6 weeks did not affect insulin levels following $12 \mathrm{~h}$ of fasting (Fig. 3B). 

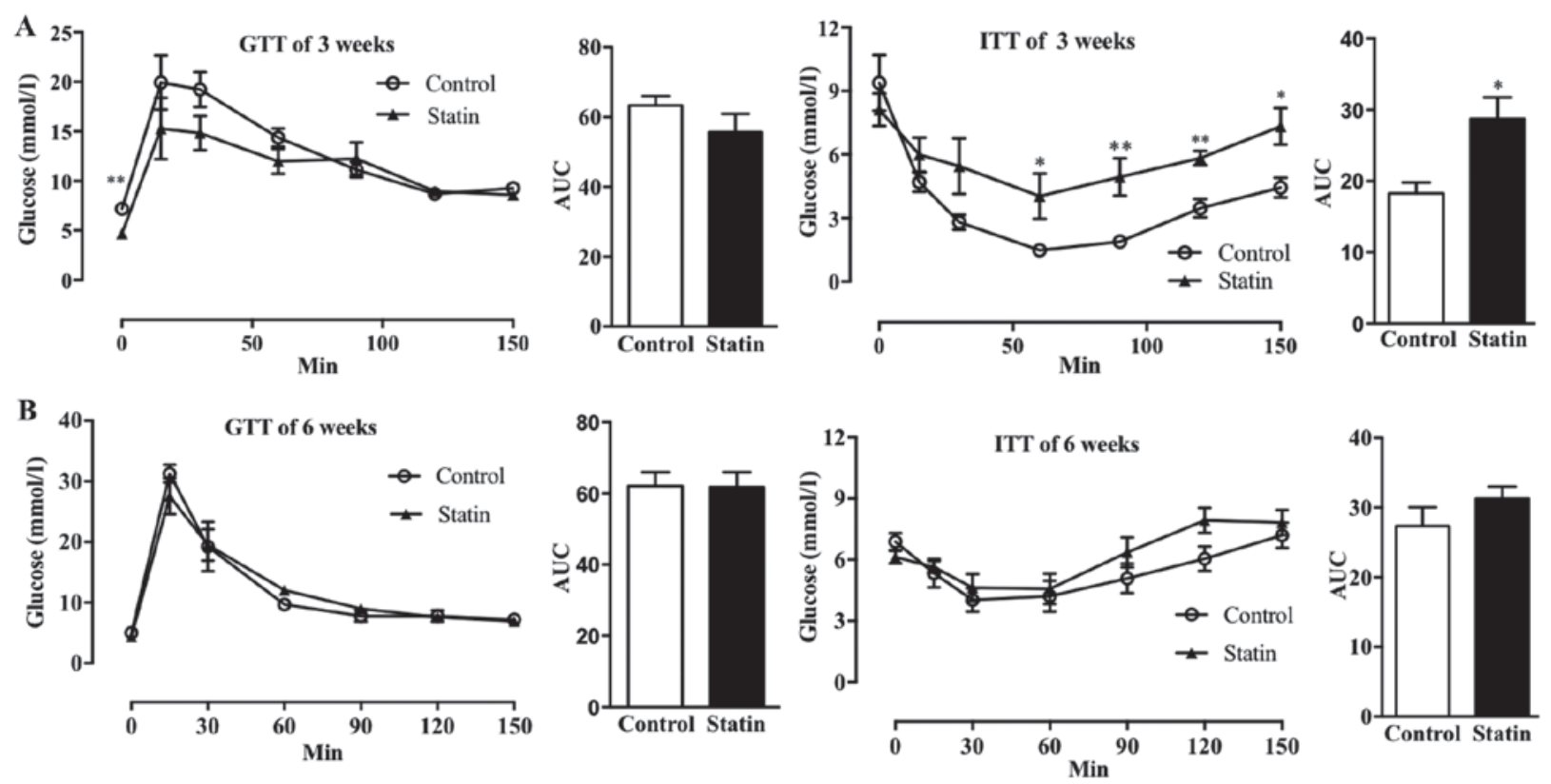

Figure 1. Effects of 3 and 6 weeks of treatment with atorvastatin on glucose homeostasis in C57BL/6j mice. GTT (AUC of GTT, left) and ITT (AUC of ITT; right) were performed following (A) 3 weeks and (B) 6 weeks of treatment with atorvastatin. $n=6 /$ group. Data are expressed as the mean \pm standard error. "P<0.05, ${ }^{*} \mathrm{P}<0.01$ vs. respective control. GTT, glucose tolerance tests; AUC, area under the curve; ITT, insulin tolerance tests.
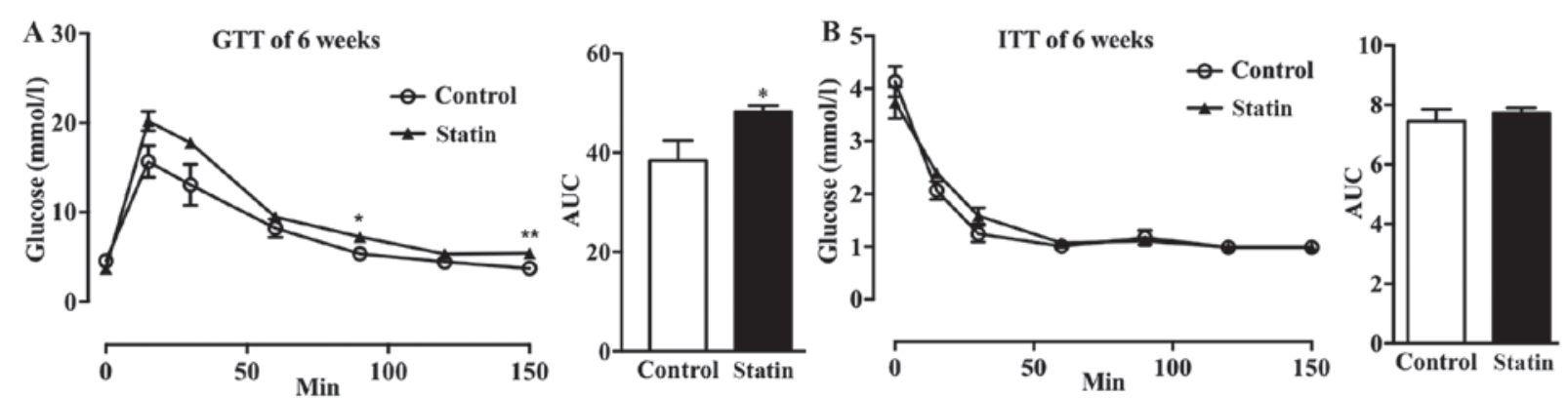

Figure 2. Effects of 6 weeks of treatment with atorvastatin on glucose homeostasis in mice with hyperlipidemia. (A) GTT and AUC of GTT and (B) ITT and AUC of ITT were performed following 6 weeks of treatment with atorvastatin. $\mathrm{n}=6 /$ group. Data are expressed as the mean \pm standard error. "P<0.05, ${ }^{* *} \mathrm{P}<0.01$ vs. respective control. GTT, glucose tolerance tests; AUC, area under the curve; ITT, insulin tolerance tests.

Treatment with atorvastatin suppresses LDLR expression in the pancreas of $C 57 B L / j$ mice. To study whether treatment with atorvastatin may affect LDLR expression in the pancreas and liver, the protein and mRNA levels of LDLR were measured by western blotting and PCR. It was observed that 6 weeks of treatment with atorvastatin significantly reduced LDLR protein in the pancreas $(\mathrm{P}<0.05)$, and this result was additionally confirmed with PCR, which demonstrated that LDLR mRNA expression was altered significantly (Fig. 4A; $\mathrm{P}<0.05$ ). As it is known that ABCA1 is a key receptor that mediates cellular cholesterol efflux, $\mathrm{ABCA} 1$ expression was additionally examined; however, no alterations in ABCA1 expression were observed in the pancreas with acute atorvastatin administration (Fig. 4A) (26). Contrary to the findings in the pancreas, it was identified that 6 weeks of treatment with atorvastatin did not affect expression of LDLR and ABCA1 at the protein and mRNA levels in the liver (Fig. 4B).

To test whether the effect of atorvastatin on LDLR expression may be affected by hyperlipidemia, the LDLR expression was measured in the pancreas and liver of ApoE-deficient mice. It was observed that 6 weeks of treatment with atorvastatin did not affect the protein and mRNA expression levels of LDLR in the pancreas (Fig. 5A). Furthermore, it was identified that treatment with atorvastatin did not affect the protein and mRNA expression of LDLR in the liver (Fig. 5B).

Treatment with atorvastatin suppresses LDLR expression in pancreatic islets. To test whether atorvastatin may affect LDLR expression in pancreatic islets, increasing concentrations of atorvastatin were used to treat adhered islets from C57BL/6j mice for $48 \mathrm{~h}$. It was identified that incubation with atorvastatin affected LDLR expression in islets in a concentration-dependent manner (Fig. 6). Subsequent to analyzing the fluorescence intensity by using ImageJ software, it was observed that islets incubated with a high dose of atorvastatin (100 $\mathrm{nM}$ ) exhibited a significantly decreased fluorescence intensity compared with the $0 \mathrm{~nm}$ group (Fig. 6B; $\mathrm{P}<0.05$ ). 

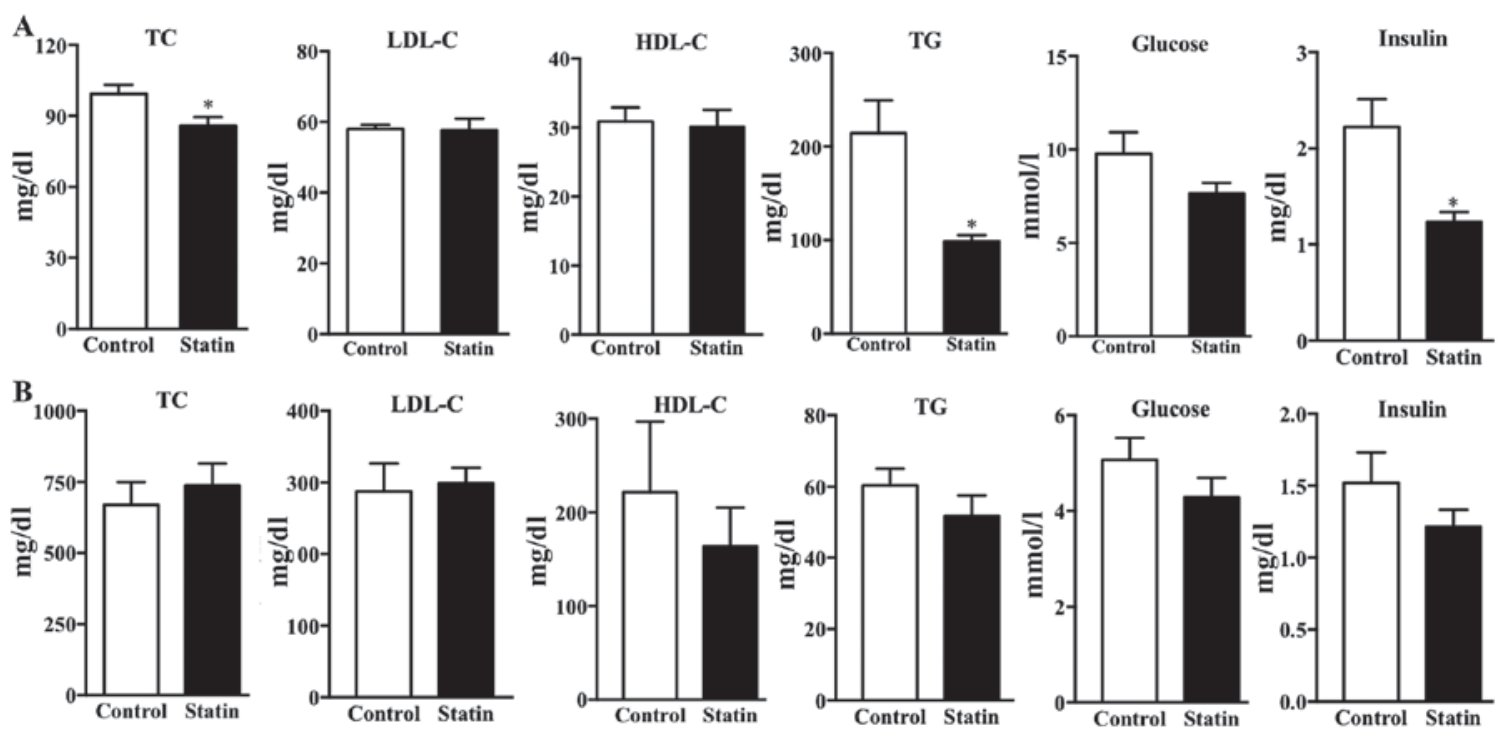

Figure 3. Effects of treatment with atorvastatin on the lipid profile, blood glucose and insulin levels in the two types of mice. Plasma TC, LDL-C, HDL-C, TG, glucose and insulin levels were determined following 6 weeks of treatment with atorvastatin in (A) C57BL/6j mice and (B) apolipoprotein E-deficient mice. $\mathrm{n}=6$ /group. Data are expressed as the mean \pm standard error. ${ }^{*} \mathrm{P}<0.05$ vs. respective control. TC, total cholesterol; LDL-C, low-density lipoprotein cholesterol; HDL-C, high-density lipoprotein cholesterol; TG, total triglycerides.

A

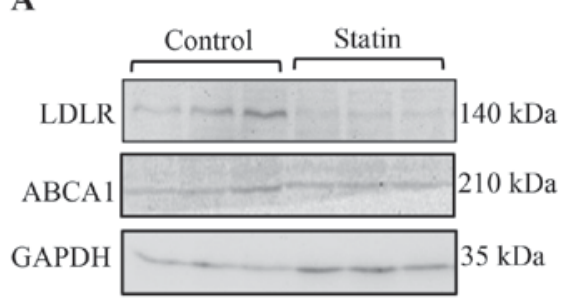

B

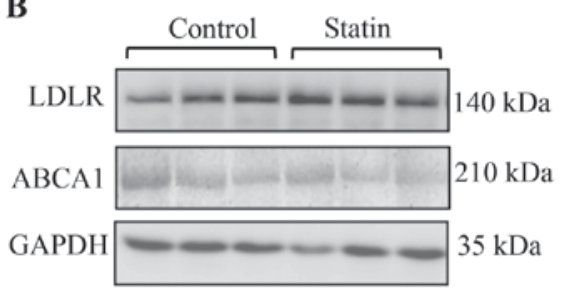

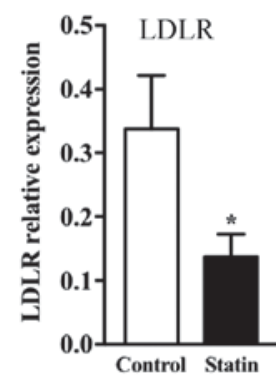
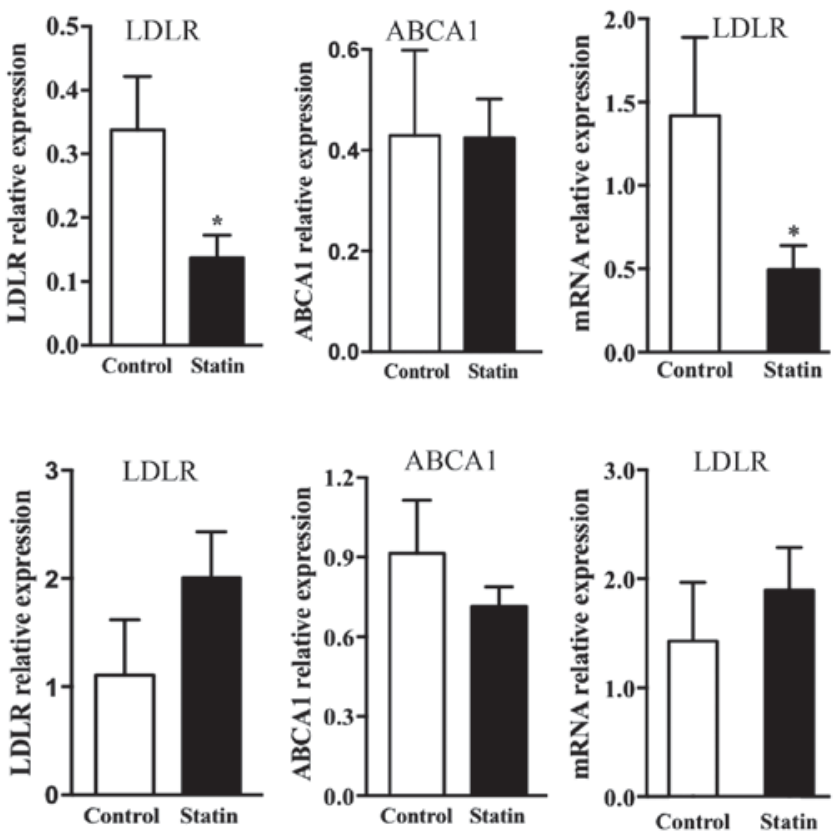

Figure 4. Expression of LDLR and ABCA1 in the pancreas and liver of C57BL/6j mice following 6 weeks of treatment with atorvastatin. Immunoblot analysis and quantification of LDLR and ABCA1, and relative expression of LDLR mRNA, in the (A) pancreas (B) and liver of C57BL/6j mice. $\mathrm{n}=6 / \mathrm{group}$. Data are expressed as the mean \pm standard error. ${ }^{*} \mathrm{P}<0.05$ vs. respective control. LDLR, low-density lipoprotein receptor; ABCA1, ATP-binding cassette transporter A1.

Short-term use of atorvastatin induces an increase in PCSK9 in the pancreas. To investigate the possible regulation of LDLR by atorvastatin, the protein expression of SREBP-2, PCSK9 and IDOL was measured in the pancreas of C57BL/6j mice. It was observed that 6 weeks of treatment with atorvastatin did not affect SREBP-2 or IDOL expression; whereas, treatment with atorvastatin significantly increased PCSK9 expression in the pancreas compared with the control (Fig. 7A; $\mathrm{P}<0.05$ ). To confirm these results, RT-qPCR was used to measure the mRNA expression of SREBP-2, PCSK9 and IDOL in the pancreas. It was observed that the mRNA expression of PCSK9 was upregulated by treatment with atorvastatin; however, SREBP-2 and IDOL were not affected (Fig. 7B). Furthermore, given that plasma PCSK9 may affect LDLR expression in peripheral tissues, a commercial ELISA kit was used to detect plasma PCSK9 expression levels. It was identified that 6 weeks of treatment with atorvastatin did not affect plasma PCSK9 expression levels (Fig. 7C). A schematic diagram represents the regulation of hepatic LDLR by statins: Statins upregulate LDLR via SREBP-2; SREBP-2 additionally increases transcription of PCSK9 to degrade LDLR; and cellular cholesterol 

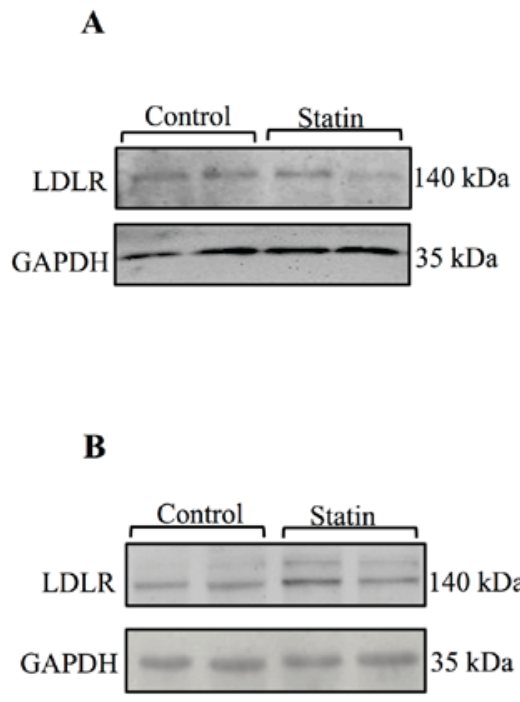
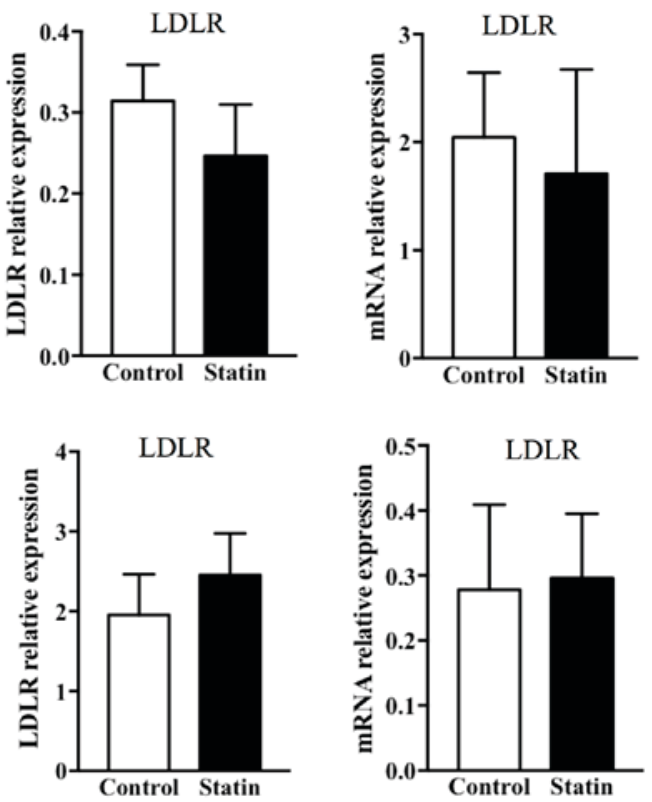

Figure 5. Expression of LDLR in the pancreas and liver of hyperlipidemic mice following 6 weeks of treatment with atorvastatin. Immunoblot analysis and quantification of LDLR and relative expression of the LDLR mRNA in (A) the pancreas and (B) the liver. $n=4$ /group. Data are expressed as the mean \pm standard error. LDLR, low-density lipoprotein receptor.
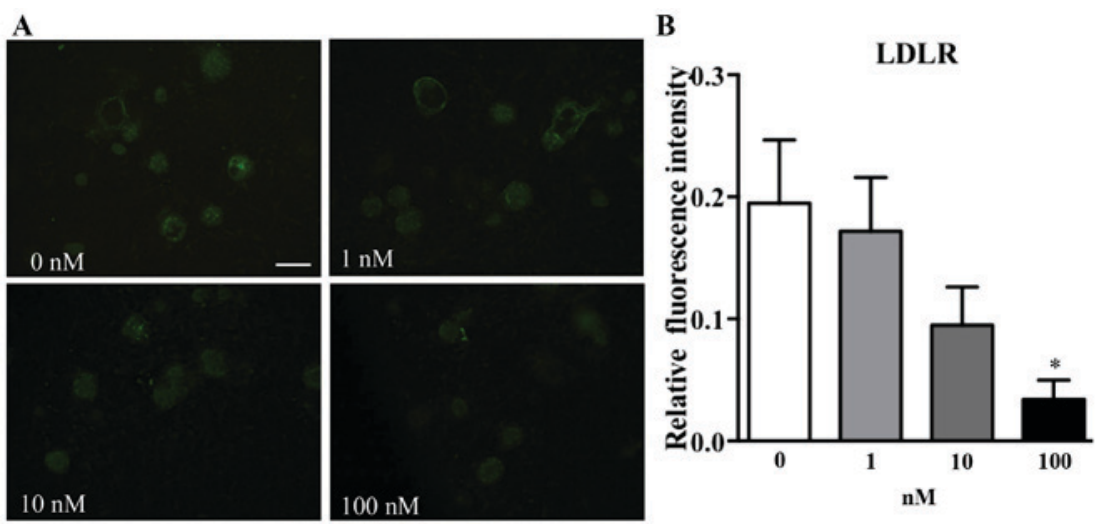

Figure 6. Expression of LDLR in pancreatic islets of C57BL/6j mice following treatment with atorvastatin. (A) Immunofluorescence staining of adhered islets with various concentrations of atorvastatin (magnification, $\mathrm{x} 4$; scale bar, $100 \mu \mathrm{m}$ ). (B) Relative fluorescence intensity was quantified. Data are expressed as the mean \pm standard error. ${ }^{*} \mathrm{P}<0.05$ vs. $0 \mathrm{nM}$ group. LDLR, low-density lipoprotein receptor.

accumulation may activate LXR, which upregulates IDOL to degrade LDLR (Fig. 7D).

\section{Discussion}

Statins are 3-hydroxy-3-methyl-glutaryl coenzyme-A reductase inhibitors, which are used to decrease blood LDL-C levels by inhibiting cellular cholesterol synthesis and upregulating LDLR expression levels in the liver and peripheral tissues (27). Although previous research suggests that statins increase the risk of new-onset T2DM, it is noteworthy that statins are highly effective for the prevention of CVD in individuals with or without DM (28). A recent study additionally concluded that the net absolute benefit observed with statin therapy in such individuals is $>50$ times greater compared with any putative effect on DM (29). As statins have an important role in the primary and secondary prevention of CVD, a mechanistic understanding of the diabetogenic effect of statins requires investigation. However, there are inconsistent findings on the diabetogenic effect of statins in animal experiments (28). A previous study conducted by the present team demonstrated that long-term treatment with atorvastatin does not affect glucose homeostasis in rabbits with normal blood lipid levels (7). Given that adaptation may occur in islets when experimental animals are subjected to long-term treatment with atorvastatin, it was hypothesized that acute administration of atorvastatin may affect glucose hemostasis. Notably, the present study supports the hypothesis that short-term administration of atorvastatin may slightly affect glucose homeostasis in normal and hyperlipidemic mice. In clinical studies, treatment with statins has been associated with the risk of new-onset T2DM; there is additional evidence to suggest that statins may induce the onset of T2DM (29,30). Although diabetic rodent models are useful for the majority of diabetes studies, these animals usually have impaired pancreatic islets and present dysfunction of $\beta$ cells, which may not be suitable for observation of early changes in 
A

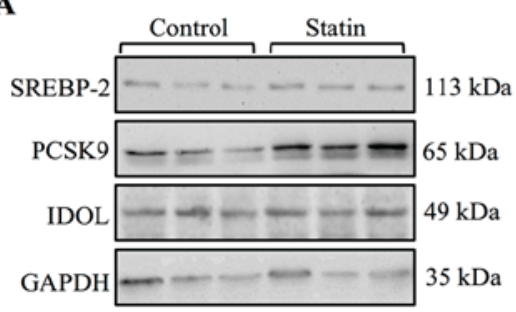

SREBP-2

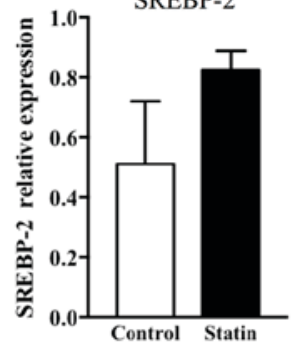

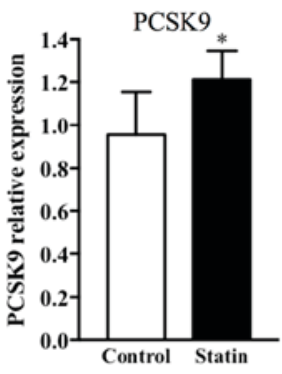

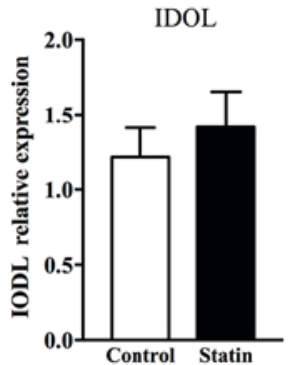

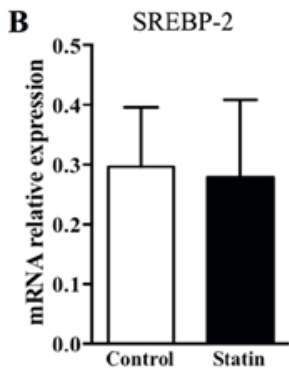
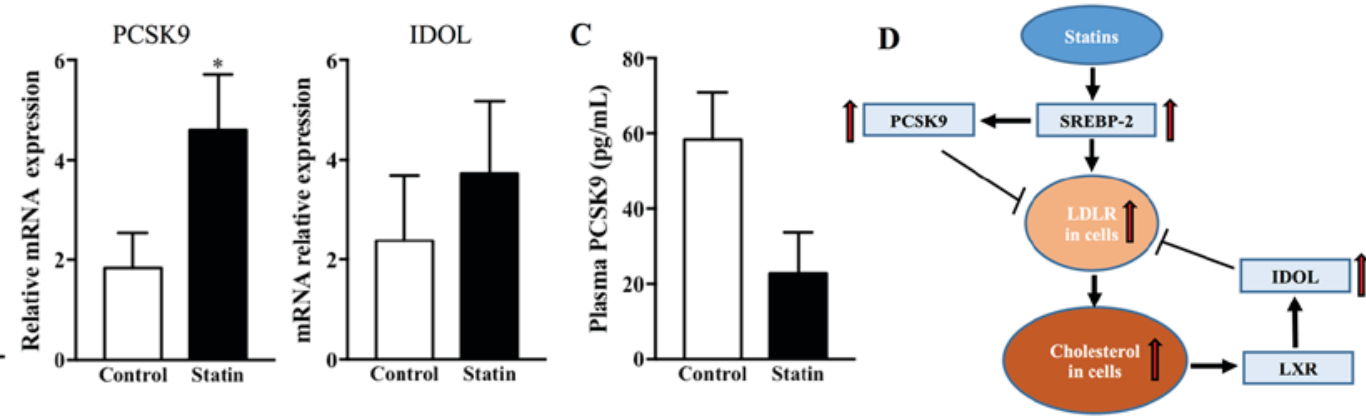

Figure 7. Expression of SREBP-2, PCSK 9 and IDOL in the pancreas of C57BL/6j mice following 6 weeks of treatment with atorvastatin. (A) Protein expression of SREBP-2, PCSK9 and IDOL was quantified by western blotting. $n=4 /$ group. (B) mRNA expression of SREBP-2, PCSK9 and IDOL was assessed by reverse transcription-quantitative polymerase chain reaction. n=4/group. (C) Plasma PCSK9 was quantified using an ELISA kit. n=10/group. (D) A schematic diagram representing the regulation of hepatic LDLR by statins: Statins upregulate LDLR via SREBP-2; SREBP-2 additionally increases transcription of PCSK9 to degrade LDLR; and cellular cholesterol accumulation may activate LXR, which upregulates IDOL to degrade LDLR. Data are expressed as the mean \pm standard error. ${ }^{~} \mathrm{P}<0.05$ vs. respective control. PCSK9, proprotein convertase subtilisin/kexin type 9; SREBP-2, sterol regulatory element-binding protein 2; LDLR, low-density lipoprotein receptor; IDOL, E3 ubiquitin-protein ligase MYLIP; LXR, oxysterols receptor LXR- $\alpha$.

the diabetogenic process or a slight effect of statins on normal islets (31). It was hypothesized that the diabetogenic effect of statins may contribute to LDLR-mediated LDL-C uptake in $\beta$ cells, and hyperlipidemia may be involved in the diabetogenic effect of statins. Therefore, normal C57BL/J and hyperlipidemic ApoE-deficient mice were examined in the present study.

On the basis of previous studies, statins may increase the transcription of LDLRs in the liver by upregulating SREBP-2. As a transcription factor, SREBP-2 additionally upregulates PCSK9 to induce the degradation of LDLR (27). Statins may promote an increase in IDOL, which serves as a ubiquitin ligase to degrade LDLR and may reduce LDLR expression (32). As statins may dually upregulate and downregulate LDLR, the abundance of the LDLR protein is not markedly increased in the liver (33). In contrast to the liver, the pancreas and islets may not be fully subjected to such dual regulation. In the present study, it was observed that atorvastatin suppressed LDLR expression in the pancreas and islets, whereas this phenomenon was not observed in the liver. Furthermore, it was not observed that atorvastatin affected LDLR expression in the pancreas and liver in hyperlipidemic mice. As mentioned previously, LDLR expression is primarily regulated by SREBP-2, PCSK9 and IDOL. Therefore, these genes were investigated in the pancreas. Interestingly, compared with no difference in plasma PCSK9, treatment with atorvastatin may promote an increase in PCSK9 in the pancreas, indicating that decreased LDLR may be attributed to upregulated PCSK9 in situ.

As previously mentioned, upregulation of LDLR may enhance LDLR-mediated LDL-C (or modified LDL-C) uptake and causes dysfunction or cytotoxicity in these cells (2). LDLR therefore provides an association between treatment with statins and new-onset T2DM. Although the present data demonstrated that atorvastatin decreases LDLR in the pancreas, the pathological role of LDLR in T2DM requires further investigation. Firstly, it is unclear whether treatment with atorvastatin may induce a similar effect on LDLR expression in the pancreas and islets of humans, and this effect may be enhanced or weakened in patients with hyperlipidemia or T2DM. Secondly, ApoE-deficient mice present hypercholesterolemia due to accumulation of remnant lipoproteins compared with LDLs, which is not completely consistent with the physiopathological process of patients with hyperlipidemia or FH. Therefore, a clinical study may provide novel insight into the pathological role of LDLR in the diabetogenic effect of statins. Notably, it was additionally identified that atorvastatin did not promote an increase in ABCA1 in the liver and pancreas. Given that ABCA1 is a pivotal receptor for mediating cholesterol efflux, whether atorvastatin may enhance the ABCA1-mediated cholesterol efflux in mice requires determination (34).

In conclusion, the present study presents novel findings on the effect of acute administration of atorvastatin on disturbing glucose homeostasis. It was additionally demonstrated that acute administration of atorvastatin downregulates LDLR expression in the pancreas of normal mice; however, this reduction in LDLR was not observed in hyperlipidemic mice. Furthermore, the present data demonstrated that LDLR expression in the pancreas is more affected by atorvastatin compared with in the liver of mice with normal blood lipid levels, suggesting that the role of LDLR in the diabetogenic effect of statins requires further investigation. 


\section{Acknowledgements}

Not applicable.

\section{Funding}

The present study was supported by the National Natural Science of China (grant nos. 81400328 and 81773795), China Postdoctoral Science Foundation (grant nos. 2015M582800 and 2016T90972), Natural Science Basic Research Plan in Shaanxi Province of China (grant nos. 2016JM8025 and 2016SF-107) and Scientific Research Fund of Shannxi Provincial Education Department (grant no. 17JS116).

\section{Availability of data and materials}

All data generated or analyzed during the present study are included in this published article.

\section{Authors' contributions}

QY, CX and SW contributed to the experimental design, discussion of result and critical revision of the manuscript. QY contributed to the drafting of the manuscript. QY, FW, XM, YG and YW conducted the experiments. All authors have read and approved the final manuscript.

\section{Ethics approval and consent to participate}

The experimental protocols were approved by the Laboratory Animal Administration Committee of Xi'an Medical University (Institutional Animal Care and Use Committee; permit no. XYJZS-1207011).

\section{Patient consent for publication}

Not applicable.

\section{Competing interests}

The authors declare that they have no competing interests.

\section{References}

1. Brault M,Ray J, Gomez YH,Mantzoros CS and Daskalopoulou SS: Statin treatment and new-onset diabetes: A review of proposed mechanisms. Metabolism 63: 735-745, 2014.

2. Yu Q, Chen Y and Xu CB: Statins and new-onset diabetes mellitus: LDL receptor may provide a key link. Front Pharmacol 8: 372 2017.

3. Besseling J, Kastelein JJ, Defesche JC, Hutten BA and Hovingh GK: Association between familial hypercholesterolemia and prevalence of type 2 diabetes mellitus. JAMA 313 $1029-1036,2015$

4. Yu Q, Su X and Liu E: Could familial hypercholesterolemia oppose the diabetogenic effect of statin? Comments on a new SAFEHEART study. Int J Cardiol 202: 954-955, 2016.

5. Ishikawa M, Iwasaki Y, Yatoh S, Kato T, Kumadaki S, Inoue N, Yamamoto T, Matsuzaka T, Nakagawa Y, Yahagi N, et al: Cholesterol accumulation and diabetes in pancreatic beta-cell-specific SREBP-2 transgenic mice: A new model for lipotoxicity. J Lipid Res 49: 2524-2534, 2008.

6. Brunham LR, Kruit JK, Verchere CB and Hayden MR: Cholesterol in islet dysfunction and type 2 diabetes. J Clin Invest 118: 403-408, 2008.
7. Cheng D, Wang Y, Gao S, Wang X, Sun W, Bai L, Cheng G, Chu Y, Zhao S and Liu E: Atorvastatin delays the glucose clearance rate in hypercholesterolemic rabbits. Biomed Pharmacother 72: 24-29, 2015.

8. Capel F, Chabrier G, Pitois E, Rigaudière JP, Le Plenier S, Durand C, Jouve C, de Bandt JP, Cynober L and Moinard C: Combining citrulline with atorvastatin preserves glucose homeostasis in a murine model of diet-induced obesity. Br J Pharmacol 172: 4996-5008, 2015.

9. Liang J, Yin K, Cao X, Han Z, Huang Q, Zhang L, Ma W, Ding F, Bi C, Feng D, et al: Attenuation of low ambient temperature-induced myocardial hypertrophy by atorvastatin via promoting Bcl-2 expression. Cell Physiol Biochem 41: 286-295, 2017.

10. Ren XM, Zuo GF, Wu W, Luo J, Ye P, Chen SL and Hu ZY: Atorvastatin alleviates experimental diabetic cardiomyopathy by regulating the GSK-3 $\beta-\mathrm{PP} 2 \mathrm{Ac}-\mathrm{NF}-\kappa \mathrm{B}$ signaling axis. PLoS One 11: e0166740, 2016.

11. Wu W, Zhao L, Yang P, Zhou W, Li B, Moorhead JF, Varghese Z, Ruan XZ and Chen Y: Inflammatory stress sensitizes the liver to atorvastatin-induced injury in ApoE-/-mice. PLoS One 11: e0159512, 2016.

12. Lee S, Lee Y, Kim J, An J, Kim K, Lee H, Kong H, Song Y and Kim K: Atorvastatin and rosuvastatin improve physiological parameters and alleviate immune dysfunction in metabolic disorders. Biochem Biophys Res Commun 478: 1242-1247, 2016.

13. Roth L, Rombouts M, Schrijvers DM, Martinet W and De Meyer GR: Cholesterol-independent effects of atorvastatin prevent cardiovascular morbidity and mortality in a mouse model of atherosclerotic plaque rupture. Vascul Pharmacol 80: 50-58, 2016.

14. Han H, Chen Y, Zhu J, Ni J, Sun J and Zhang R: Atorvastatin attenuates p-cresyl sulfate-induced atherogenesis and plaque instability in ApoE knockout mice. Mol Med Rep 14: 3122-3128, 2016.

15. Bruder-Nascimento T, Callera GE, Montezano AC, He Y, Antunes TT, Nguyen Dinh Cat A, Tostes RC and Touyz RM: Vascular injury in diabetic $\mathrm{db} / \mathrm{db}$ mice is ameliorated by atorvastatin: Role of Rac1/2-sensitive Nox-dependent pathways. Clin Sci (Lond) 128: 411-423, 2015.

16. Park SH, Sung YY, Nho KJ and Kim HK: Protective activity ethanol extract of the fruits of Illicium verum against atherogenesis in apolipoprotein E knockout mice. BMC Complement Altern Med 15: 232, 2015.

17. van den Hoek AM, van der Hoorn JW, Maas AC, van den Hoogen RM, van Nieuwkoop A, Droog S, Offerman EH, Pieterman EJ, Havekes LM and Princen HM: APOE*3Leiden. CETP transgenic mice as model for pharmaceutical treatment of the metabolic syndrome. Diabetes Obes Metab 16: 537-544, 2014.

18. Yu Q, Liu Z, Waqar AB, Ning B, Yang X, Shiomi M, Graham MJ, Crooke RM, Liu E, Dong S and Fan J: Effects of antisense oligonucleotides against C-reactive protein on the development of atherosclerosis in WHHL rabbits. Mediators Inflamm 2014: 979132, 2014

19. Yu Q, Wang Y, Yu Y, Li Y, Zhao S, Chen Y, Waqar AB, Fan J and Liu E: Expression of TRPV1 in rabbits and consuming hot pepper affects its body weight. Mol Biol Rep 39: 7583-7589, 2012.

20. Livak KJ and Schmittgen TD: Analysis of relative gene expression data using real-time quantitative PCR and the 2(-Delta Delta C(T)) method. Methods 25: 402-408, 2001.

21. Li DS, Yuan YH, Tu HJ, Liang QL and Dai LJ: A protocol for islet isolation from mouse pancreas. Nat Protoc 4: 1649-1652, 2009.

22. Zhao W and Zhao SP: Different effects of statins on induction of diabetes mellitus: An experimental study. Drug Des Devel Ther 9: 6211-6223, 2015.

23. Jensen EC: Quantitative analysis of histological staining and fluorescence using ImageJ. Anat Rec (Hoboken) 296: 378-381, 2013.

24. Ansar S, Koska J and Reaven PD: Postprandial hyperlipidemia, endothelial dysfunction and cardiovascular risk: Focus on incretins. Cardiovasc Diabetol 10: 61, 2011.

25. Bot I, Jukema JW, Lankhuizen IM, van Berkel TJ and Biessen EA: Atorvastatin inhibits plaque development and adventitial neovascularization in ApoE deficient mice independent of plasma cholesterol levels. Atherosclerosis 214: 295-300, 2011. 
26. Du XM, Kim MJ, Hou L, Le Goff W, Chapman MJ, Van Eck M, Curtiss LK, Burnett JR, Cartland SP, Quinn CM, et al: HDL particle size is a critical determinant of ABCA1-mediated macrophage cellular cholesterol export. Circ Res 116: 1133-1142, 2015.

27. Goldstein JL and Brown MS: A century of cholesterol and coronaries: From plaques to genes to statins. Cell 161: 161-172, 2015.

28. Axsom K, Berger JS and Schwartzbard AZ: Statins and diabetes: The good, the bad and the unknown. Curr Atheroscler Rep 15: 299, 2013.

29. Hennekens CH, Teng B and Pfeffer MA: Statins and diabetes: Current perspectives and implications for clinicians. Am J Med 130: 504-506, 2017.

30. Sattar N and Taskinen MR: Statins are diabetogenic-myth or reality? Atheroscler Suppl 13: 1-10, 2012.

31. Furman BL: Streptozotocin-induced diabetic models in mice and rats. Curr Protoc Pharmacol 70: 5.47.1-20, 2015.
32. Hong C, Marshall SM, McDaniel AL, Graham M, Layne JD, Cai L, Scotti E, Boyadjian R, Kim J, Chamberlain BT, et al: The LXR-Idol axis differentially regulates plasma LDL levels in primates and mice. Cell Metab 20: 910-918, 2014.

33. Attie AD and Seidah NG: Dual regulation of the LDL receptor-some clarity and new questions. Cell Metab 1: 290-292, 2005.

34. Kruit JK, Kremer PH, Dai L, Tang R, Ruddle P, de Haan W, Brunham LR, Verchere CB and Hayden MR: Cholesterol efflux via ATP-binding cassette transporter A1 (ABCA1) and cholesterol uptake via the LDL receptor influences cholesterol-induced impairment of beta cell function in mice. Diabetologia 53: 1110-1119, 2010.

This work is licensed under a Creative Commons Attribution-NonCommercial-NoDerivatives 4.0 International (CC BY-NC-ND 4.0) License. 